\title{
Análise socioeconômica de alternativas para o transporte ferroviário de passageiros em uma rede regional
}

\author{
Cassiano Augusto Isler ${ }^{1}$, João Alexandre Widmer ${ }^{2}$
}

1Departamento de Engenharias da Mobilidade, Universidade Federal de Santa Catarina, cassiano.isler@ufsc.br 2Departamento de Engenharia de Transportes, Universidade de São Paulo, widmer@sc.usp.br

\section{Recebido:}

20 de fevereiro de 2017

Aceito para publicação:

13 de julho de 2017

Publicado:

29 de outubro 2017

Editor de área:

Renato Lima

\section{Palavras-chaves:}

Ferrovia,

Passageiro,

Escolha Modal,

Análise Socioeconômica.

\section{Keywords:}

Railway,

Passenger,

Mode Choice,

Socioeconomic Analysis.

DOI:10.14295/transportes.v25i3.1332

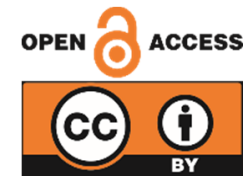

\begin{abstract}
RESUMO
Apesar da divulgação de estudos recentes sobre o transporte ferroviário de passageiros no Brasil, não existe na literatura uma comparação entre tecnologias para oferta desses serviços. Ao considerar uma hierarquia de serviços ferroviários, este artigo tem o objetivo de comparar a operação exclusiva de trens com velocidade média de 150 km/h (HPT) e 300 km/h (HST) em uma rede hipotética na Região Sudeste do país. Pelos resultados de uma Análise Custo-Benefício, os valores de investimentos estimados para construção da rede de HST são 5,36\% superiores à de HPT. No âmbito estritamente econômico, sob diferentes cenários, nenhuma das tecnologias é viável de ser operada sem subsídio. Do ponto de vista socioeconômico, os benefícios sociais superam os custos econômicos na rede de HPT e HST quando as tarifas são, respectivamente, de $R \$ 0,40 / \mathrm{km}$ e $\mathrm{R} \$ 0,75 / \mathrm{km}$, ultrapassando o valor de 1,50 para a Relação Benefício-Custo somente pela operação de HST em cenários específicos.
\end{abstract}

\begin{abstract}
Despite the recent studies on the railway passenger transport in Brazil there is not a comparison among different technologies for the proposed services in the literature. This paper aims to compare the exclusive operation of trains with average speed of $150 \mathrm{~km} / \mathrm{h}$ (HPT) and $300 \mathrm{~km} / \mathrm{h}$ (HST) over a hypothetical network in the Southeast Region of Brazil while considering a hierarchy of different railway services. The results of a Cost-Benefit Analysis show that the estimated investment for construction of the HST network is $5.36 \%$ higher than the HPT network. In the economic level, none of the technology is feasible to be operated without subsidy under different scenarios. From the socioeconomic perspective, the social benefits surpass the economic costs when the fare of the HPT is R\$0.40/ km and the fare of the HST is R\$0.75/ $\mathrm{km}$, exceeding the value of 1.50 for the Benefit-Cost Ratio only by the operation of the HST network under specific scenarios.
\end{abstract}

\section{INTRODUÇÃO}

O cenário atual de oferta de serviços ferroviários para o transporte de passageiros difere significativamente entre países. No Brasil, a concessão da operação das ferrovias às empresas privadas não considerou uma política estratégica de operação da malha ferroviária para aquele propósito, resultando na utilização majoritária da rede para o transporte de cargas.

Apesar disso, estudos recentes consideraram a reativação do transporte ferroviário intermunicipal de passageiros. 0 Governo Federal brasileiro apresentou uma proposta de projeto de Trem de Alta Velocidade (High Speed Train - HST) para conexão das cidades de Campinas, São Paulo e Rio de Janeiro com veículos de velocidade média de $300 \mathrm{~km} / \mathrm{h}$ (TAV, 2014). Por outro lado, o Governo do Estado de São Paulo, sob representação da Companhia Paulista de Trens Metropolitanos (CPTM), apresentou propos- 
tas para conexão da Região Metropolitana de São Paulo às cidades do interior do Estado com trens de velocidade de $150 \mathrm{~km} / \mathrm{h}$ (CPTM, 2014).

Ao analisar aqueles projetos constata-se que não existe uma terminologia comum às esferas governamentais para classificação dos diferentes serviços no país. Assim, uma adaptação da proposta de Wang et al. (2012) indicada na Figura 1 pode ser utilizada para caracterização das tecnologias ferroviárias abordadas neste artigo, com o propósito de formalização da hierarquia dos serviços de transporte ferroviário de passageiros no Brasil.

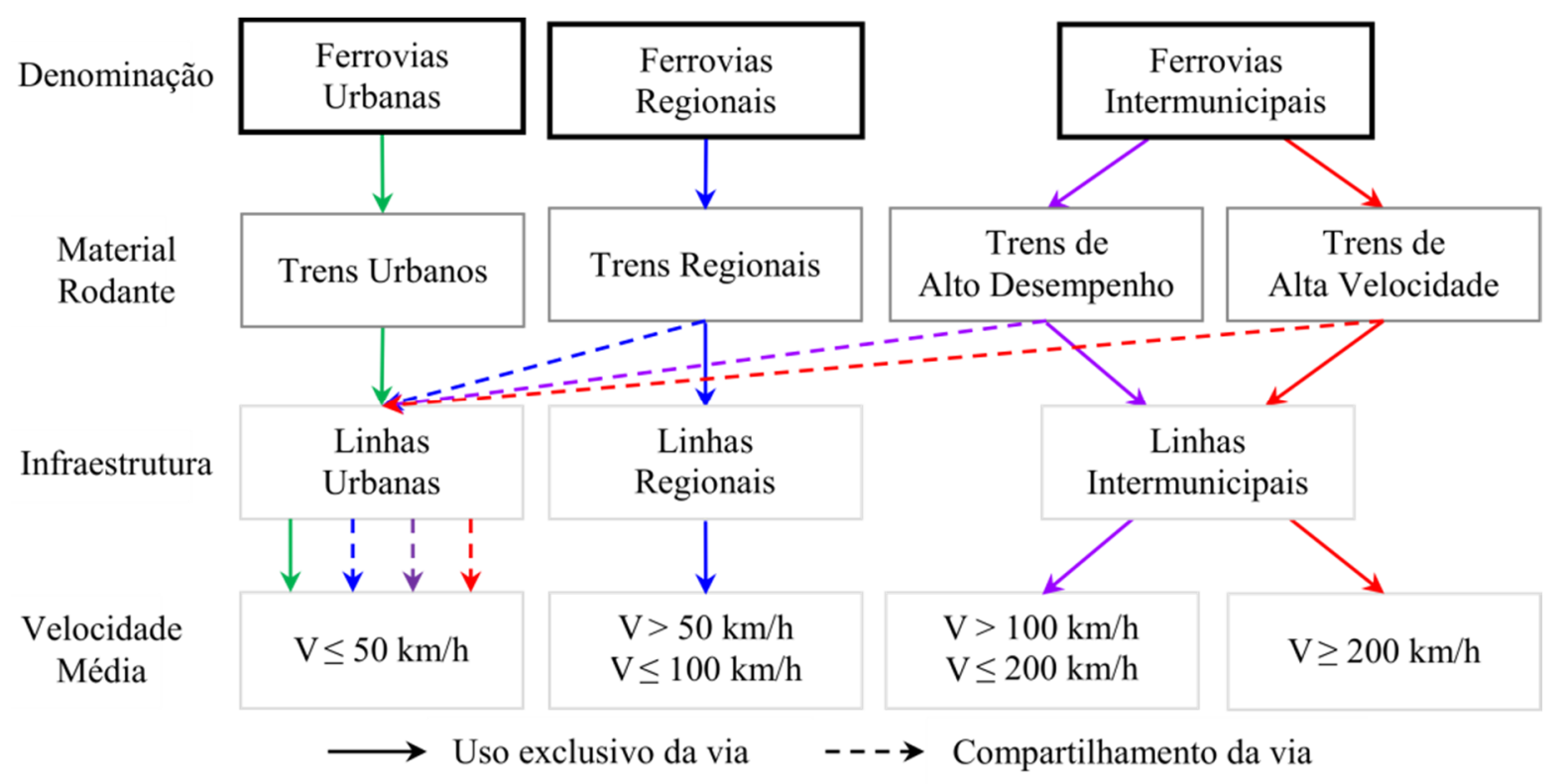

Figura 1: Proposta de hierarquia de ferrovias brasileiras para o transporte de passageiros Fonte: adaptado de Wang et al. (2012)

Especificamente no âmbito das ferrovias intermunicipais, os Trens de Alto Desempenho (High Performance Train - HPT) aproximam-se das propostas da CPTM para conexão das cidades do interior do Estado de São Paulo à capital (CPTM, 2014). Nessa mesma categoria, os HSTs podem operar nas linhas intermunicipais com tempos de viagem reduzidos pelo aumento da velocidade média dos veículos, como na proposta de conexão entre as Regiões Metropolitanas de São Paulo e do Rio de Janeiro à cidade de Campinas (TAV, 2014).

Para que seja possível avaliar uma alternativa ou comparar diferentes propostas de projetos de transporte é necessário um método cujos resultados possam ser analisados pelos tomadores de decisão. A Análise Multicritério consiste na seleção de uma alternativa entre um conjunto de soluções disponíveis para um problema com base em uma lista de critérios e seus respectivos pesos (Sartori et al., 2004; Munasinghe, 2007). Por outro lado, a Análise Custo-Benefício aborda a quantificação dos custos e benefícios econômicos e sociais de diferentes projetos em uma unidade comum (geralmente monetária), comparando-os para identificação daquele que provê maior valor para as medidas de desempenho admitidas (Boardman et al., 2011; Berechman, 2010).

No âmbito ferroviário, Dreyer (2010) apresenta uma abrangente revisão da literatura sobre as práticas de análise de projetos de HST para o transporte de passageiros na Europa. Gleave (2004) provê um panorama dos potenciais mercados a serem atendidos por essa tecnologia de transporte no Reino Unido, França, Alemanha, Itália, Japão e Austrália. Adicionalmente, De Rus e Nombela (2007) e De Rus (2008) apresentam comparações dos benefícios sociais de novas linhas de trens de alta velocidade em relação ao excedente dos usuários e operadores, e quanto aos investimentos na sua construção e operação.

Analogamente à inexistência de uma hierarquia quanto aos diferentes tipos de serviços ferroviários para o transporte de passageiros no país, constata-se que não há na literatura nacional uma comparação 
entre as tecnologias para oferta desses serviços, sobretudo quanto aos projetos recentemente propostos pelas entidades públicas brasileiras.

Nesse sentido, o objetivo deste artigo é comparar a oferta de serviços ferroviários para o transporte de passageiros na Região Sudeste do Brasil em uma rede hipotética, considerando a operação exclusiva de trens de Alto Desempenho (HPT) ou de Alta Velocidade (HST). Essa comparação é realizada por uma Análise Custo-Benefício em que são considerados os investimentos em infraestrutura necessários para viabilizar a operação dos trens, o número de viagens entre cidades específicas na Região Sudeste, a divisão modal decorrente da oferta daqueles serviços e uma formulação para cálculo dos itens de custos e benefícios sociais e econômicos pela operação dos trens na rede.

Este artigo está organizado em seis seções. 0 modelo para estimativa dos investimentos em infraestrutura é caracterizado na Seção 2 após esta Introdução. A Seção 3 contém uma descrição do método para estimativa do número de viagens entre cidades da Região Sudeste e a descrição do modelo de divisão modal. 0 equacionamento para Análise Custo-Benefício para comparação dos serviços ferroviários é brevemente descrito na quarta seção, e a Seção 5 contém os resultados das análises socioeconômicas aplicadas à rede hipotética proposta. Finalmente, na Seção 6 são resumidas as conclusões desta pesquisa e potenciais investigações futuras pertinentes ao tema.

\section{INVESTIMENTOS EM INFRAESTRUTURA}

Apesar do interesse na reativação do transporte ferroviário de passageiros no Brasil, pesquisas corroboram o argumento de que a infraestrutura ferroviária brasileira atual inviabiliza a oferta de serviços competitivos, sobretudo devido à incompatibilidade da geometria da via para operação de trens com maiores velocidades (Batista, 2006; Isler 2010).

Assim, dada a incompatibilidade da atual infraestrutura ferroviária brasileira que viabilizem a competição com outros modos de transporte em termos de tempo de viagem, considera-se necessário o estudo de novos traçados compatíveis com a operação dos HPTs e HSTs. Nessas condições, o problema de otimização de traçados ferroviários é uma alternativa metodológica para o tema, que consiste na identificação do alinhamento entre duas localidades com o menor valor de investimento total estimado (Kim, 2005).

Kang et al. (2012) apresentam uma abrangente revisão sobre as principais abordagens para resolução do problema de otimização de traçados rodoferroviários considerando os parâmetros geométricos dos alinhamentos. Dadas as pesquisas de Jong e Schonfeld (2003), Jha et al. (2006) e Samanta e Jha (2011), Kang et al. (2012) argumentam que o Algoritmo Genético (AG) tem sido a técnica mais eficiente para estimativa de valores próximos de um mínimo global para os investimentos em infraestruturas lineares rodoviárias e ferroviárias.

Mais recentemente, Lai e Schonfeld (2016) propuseram um Algoritmo Genético baseado em programação concorrente para estabelecer traçados ferroviários em áreas urbanas, dado um conjunto de múltiplas funções objetivo para identificar o alinhamento de menor valor de investimento total, e auxiliar na tomada de decisões sobre a localização de estações, incluindo os custos dessas instalações e a potencial demanda de passageiros.

Uma vez que os alinhamentos ferroviários para conexões intermunicipais na Região Sudeste do Brasil compreendem extensões significativas, um Algoritmo Genético foi implementado com base no procedimento detalhado por Jha et al. (2006), incluindo conceitos de programação paralela de modo a suprimir restrições de processamento computacional.

A programação paralela consiste na atribuição de tarefas a múltiplas máquinas simultaneamente para resolução de um problema comum, e tem sido utilizada recorrentemente para resolução de problemas de otimização (Crainic, 2012). 0 processamento de dados é realizado em um conglomerado de computadores de alto desempenho interligados em uma rede acessada pela Internet, cuja oferta de serviços configura o termo "Computação em Nuvem". Uma revisão abrangente da literatura sobre o tema pode ser encontrada em Hashem et al. (2015). 
Neste artigo, uma infraestrutura computacional disponibilizada pela Universidade de São Paulo (NuvemUSP, 2013) foi utilizada para determinação dos investimentos em novos traçados ferroviários, cujo AG para tal propósito pode ser verificado no fluxograma representado pela Figura 2.

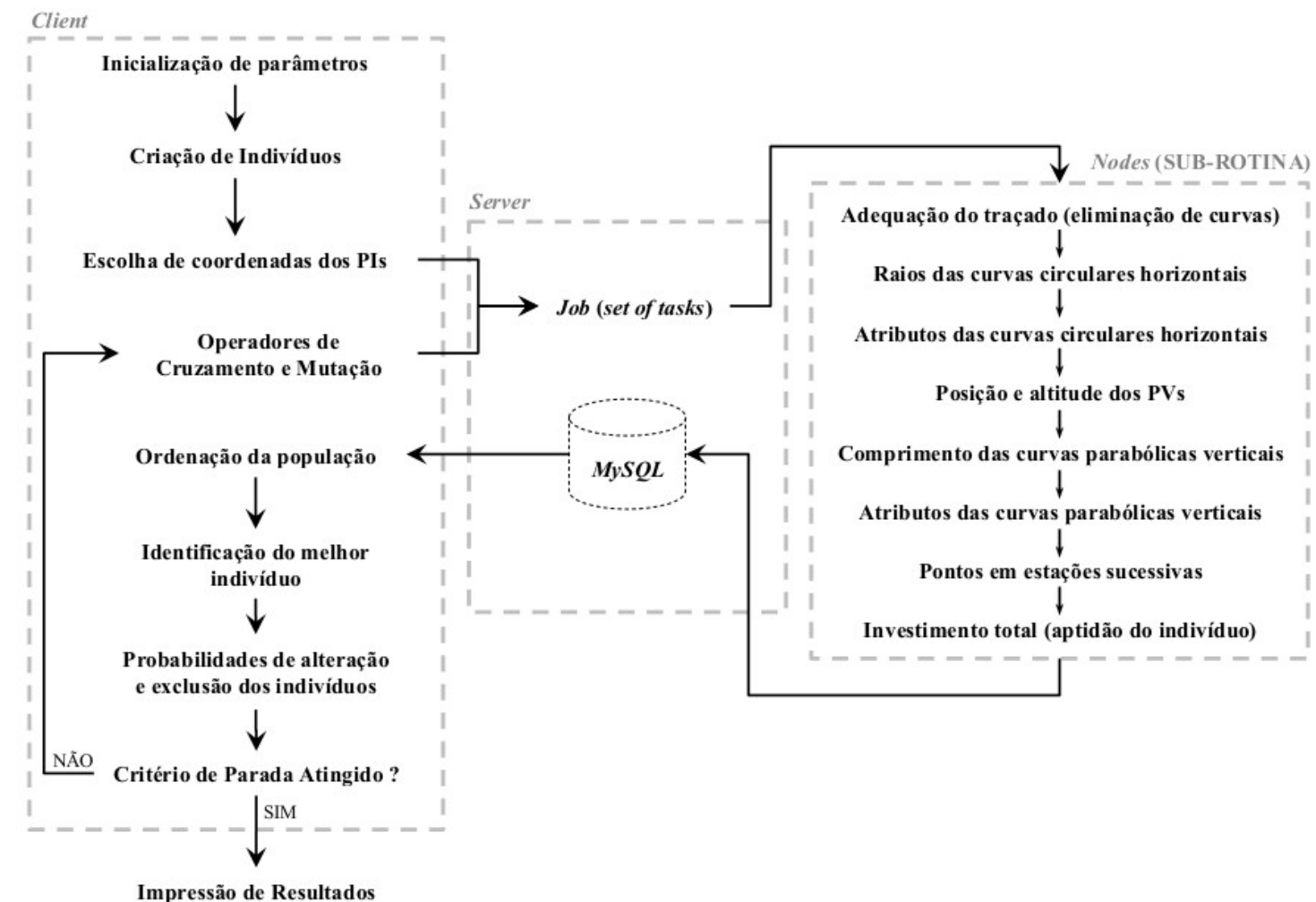

Figura 2: Fluxograma do AG para resolução do problema de otimização de traçados. Fonte: Isler (2015)

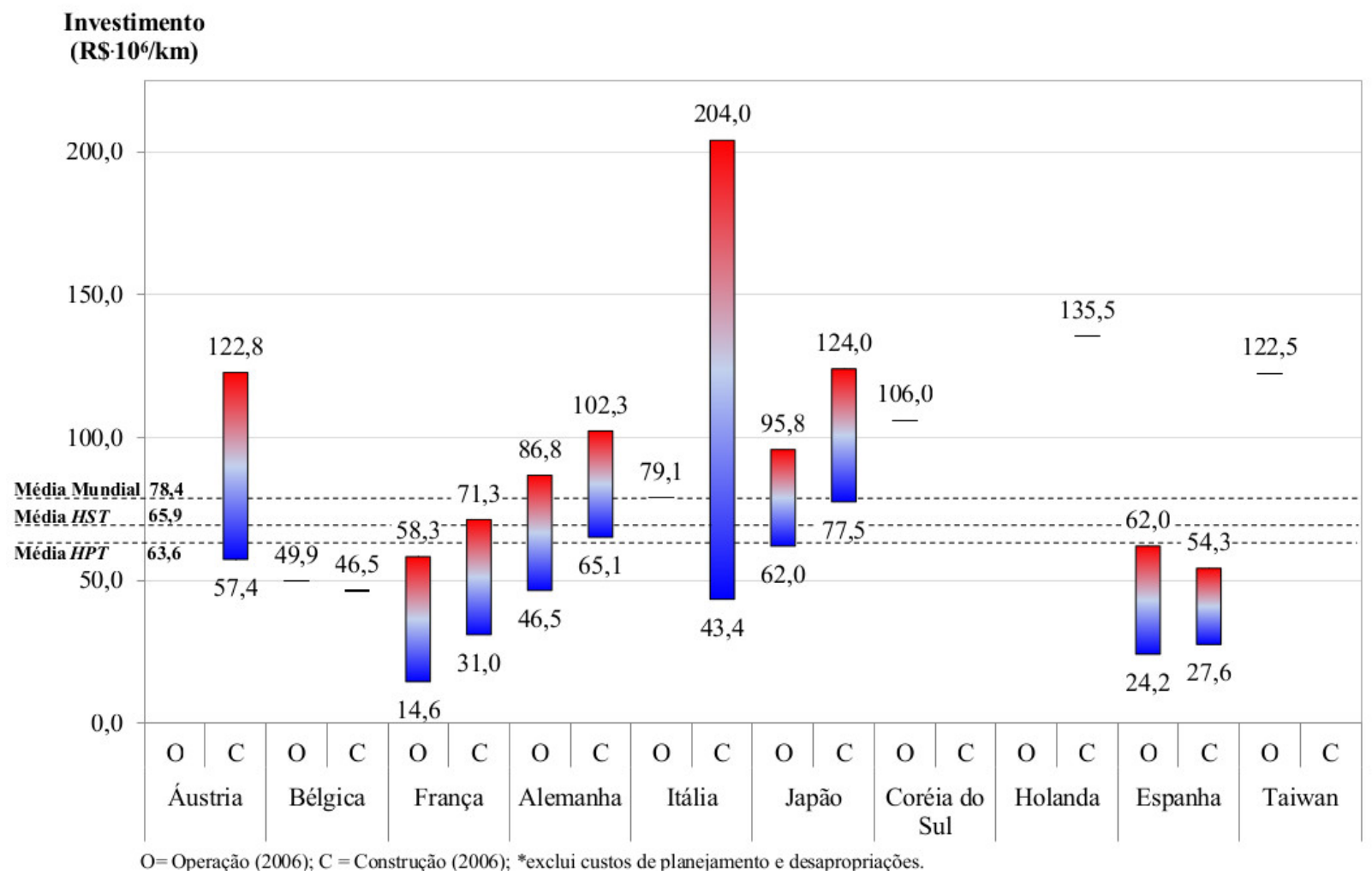

Figura 3: Valores médios de investimentos em infraestrutura obtidos pelo AG em relação aos valores mundiais observados para HST. Fonte: Adaptado De Rus et al. (2009) 
A partir da execução do AG entre cidades da Região Sudeste do Brasil, separadas entre si por diferentes condições topográficas, foram obtidas estimativas de valores de investimentos totais para a construção de infraestruturas ferroviárias para operação de HPT ou HST, cujos valores numéricos podem ser verificados em Isler (2015).

A partir de múltiplas replicações daquele algoritmo foi possível estimar valores médios dos investimentos necessários para a implantação dos traçados das respectivas tecnologias ferroviárias consideradas neste artigo, os quais são representados na Figura 3 em comparação com investimentos observados para a construção de traçados de HST no mundo conforme apresentado por De Rus et al. (2009).

\section{ESTIMATIVA DE DEMANDA}

Na pesquisa descrita neste artigo, a demanda de passageiros para os serviços ferroviários foi calculada pela estimativa do número de viagens entre cidades de médio e grande porte (com mais de 50 mil habitantes) na Região Sudeste do Brasil no ano base de 2015.

Em seguida, essas estimativas foram expandidas para um horizonte de planejamento de 35 anos (até 2050) e foi estimada a divisão modal sob a hipótese de oferta de serviços de trens de passageiros com base nos resultados de uma pesquisa de preferência declarada e modelagem de escolha discreta. Essas análises são descritas brevemente nas seções a seguir, cujo detalhamento pode ser verificado em Isler (2015).

\subsection{Número Total de Viagens no Ano Base}

Para cada modo de transporte disponível para viagens intermunicipais no ano base de 2015 foram obtidas informações sobre o número de passageiros transportados entre municípios da Região Sudeste, disponibilizadas pelas agências reguladoras do setor de transporte no país ou obtidas a partir de projetos de planejamento de transportes divulgados oficialmente.

\subsubsection{Modo Ônibus}

Diferentes autores propuseram modelos para estimar o número de viagens pelo modo ônibus (Aguiar Júnior, 2004; Gonçalves, Bez e Novaes, 2007), o qual pode ser considerado como o de maior utilização para deslocamentos intermunicipais de longa distância no Brasil. A modelagem apresentada neste artigo baseia-se em um modelo econométrico estimado por regressão linear conforme caracterizado pela Equação 1, cujos parâmetros foram estimados a partir de dados da Agência Nacional de Transporte Terrestre em pesquisa de abrangência nacional (ANTT, 2011).

$$
\begin{gathered}
\ln \left(T_{i j}\right)=\alpha+\alpha_{\mathrm{POP}} \cdot \ln \left(\text { POP }_{i} \cdot P_{O P P_{j}}\right)+\alpha_{\mathrm{OCUP}} \cdot \ln \left(\text { OCUP }_{i} \cdot \text { OCUP }_{j}\right)+\alpha_{\mathrm{DIST}} \cdot \ln (D I S T) \\
+\alpha_{\mathrm{RENDA}} \cdot \ln \left(\text { RENDA }_{i} \cdot R E N D A_{j}\right)+\alpha_{\mathrm{AUTO}} \cdot \ln \left(\text { AUTO }_{i} \cdot \text { AUTO }_{j}\right)
\end{gathered}
$$

em que $T_{i j}$ : número de viagens entre a cidades $i$ e $j$;

$P O P_{i}$ : população da cidade $i$;

$P O P_{j}$ : população da cidade $j$;

$O C U P_{i}$ : população ocupada assalariada da cidade $i$;

$O C U P_{j}$ : população ocupada assalariada da cidade $j$;

$R E N D A_{i}$ : renda per capita da cidade $i$;

$R E N D A_{j}$ : renda per capita da cidade $j$;

$A U T O_{i}$ : frota da cidade $j$;

$A U T O_{j}$ : frota da cidade $j$;

DIST : distância entre centroides das cidades (km);

$\alpha$ : parâmetro independente;

$\alpha_{\mathrm{POP}}$ : parâmetro para população;

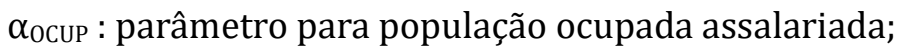


$\alpha_{\text {DIST }}$ : parâmetro para distância;

$\alpha_{\text {RENDA }}$ : parâmetro de renda per capita;

$\alpha_{\text {AUTO }}$ : parâmetro para frota.

Para estimativas desses parâmetros foram consideradas apenas as informações das bases de dados referentes às conexões entre municípios da Região Sudeste do Brasil, segregando-as em três grupos: Grupo A, com linhas rodoviárias entre capitais dos Estados (São Paulo, Rio de Janeiro, Belo Horizonte, e Vitória); Grupo B, com linhas interestaduais (excluindo entre capitais); e Grupo C, com linhas intermunicipais no mesmo Estado. Os parâmetros foram obtidos através de regressão linear Stepwise, tal que os seus valores, respectivas significâncias estatísticas e demais considerações sobre a modelagem para cada um dos grupos podem ser obtidos em Isler (2015).

\subsubsection{Modo Automóvel}

Existe uma dificuldade na modelagem do número de viagens intermunicipais e interestaduais por automóvel uma vez que, ao contrário do modo ônibus, não há disponibilidade de uma base de dados que informe a quantidade de deslocamentos realizados por aquele modo. Em geral, esses valores são obtidos através de pesquisas de campo de estudos específicos para melhoria ou implantação de sistemas de transporte.

Entretanto, o Plano Nacional de Logística e Transportes (PNLT, 2014) proposto pelo Governo Federal disponibiliza o Volume Diário Médio Anual (VDMA) dos carregamentos nas principais rodovias do país em relação o número de veículos leves (automóveis) em uma rede georeferenciada em formato de arquivo vetorial. A partir de um modelo de alocação de tráfego e reconstrução de matrizes Origem-Destino (Pitombeira Neto, Bertoncini e Loureiro, 2011; Cascetta e Nguyen, 1988) foi possível estimar o número de viagens entre pares de cidades na Região Sudeste considerando as contagens nos arcos daquela rede rodoviária.

Pela obtenção de uma matriz de distribuição de viagens pelo modo automóvel a partir da alocação de tráfego, os parâmetros da Equação (1) foram estimados por regressão linear Stepwise analogamente ao modo ônibus, considerando os três grupos de pares de cidades caracterizados anteriormente, cujos valores e detalhamento do procedimento executado podem ser consultados em Isler (2015).

\subsubsection{Modo Avião}

Assim como nas viagens por ônibus, existem pesquisas que resultaram em modelos para estimativa do número de viagens realizadas por avião no Brasil (ANAC, 1998; Alekseev e Seixas, 2002). Neste artigo a estimativa do número de viagens pelo modo aéreo deu-se de maneira análoga aos anteriores, pela estimativa dos parâmetros associados às variáveis socioeconômicas indicadas na Equação (1) entre cidades com infraestrutura aeroportuária e disponibilidade de serviços aos usuários.

O número de viagens observadas entre aeroportos nas cidades e regiões metropolitanas da Região Sudeste foi obtido da Agência Nacional de Aviação Civil (ANAC, 2012), a partir dos quais foram estimados os parâmetros da Equação (1) pelo método Stepwise, e cujos valores são indicados em Isler (2015).

\subsection{Expansão do Número de Viagens}

A expansão do número de viagens entre cidades da Região Sudeste foi realizada pela projeção dos valores das variáveis independentes da Equação (1) para cada modo de transporte sob os respectivos parâmetros estimados anteriormente.

Para cada variável independente foram obtidos valores observados no Censo de 2010 reportados pelo Instituto Brasileiro de Geografia e Estatística (IBGE, 2014a) e realizadas projeções no horizonte de 35 anos, entre 2015 e 2050. Para a projeção das variáveis independentes relacionadas à população (POP) e pessoal ocupado assalariado (OCUP) foram obtidas informações sobre o crescimento da população brasileira disponibilizado por IBGE (2014b). 
Para as variáveis relacionadas à renda per capita da população (RENDA) e frota de automóveis $(A U T O)$ optou-se pela expansão no horizonte de planejamento com base em dados de projeção da renda per capita fornecidos pelo (Ministério da Previdência Social do Brasil MPS, 2013). 0 equacionamento considerado na expansão das estimativas do ano base e os valores estimados do número de viagens em cada ano do horizonte da análise socioeconômica deste artigo podem ser verificados detalhadamente em Isler (2015).

\subsection{Divisão Modal}

Uma pesquisa de preferência declarada foi elaborada e executada para estimativa da porcentagem da população que utilizaria o modo de transporte ferroviário na eventualidade da sua oferta. A pesquisa foi realizada para identificar a propensão à escolha modal em viagens de longa distância (entre $100 \mathrm{~km}$ e $1.000 \mathrm{~km}$ ) considerando os modos de transporte automóvel (CAR), ônibus (BUS), HPT, HST e avião (AIR).

De maneira sucinta, um conjunto de questões resultantes de um planejamento de experimento ortogonal foi diagramado em uma plataforma on-line de realização da pesquisa (Qualtrics, 2016) e foram obtidas respostas de potenciais usuários localizados na Região Sudeste do Brasil pela contratação de uma empresa especializada (Livra, 2013).

A aplicação desses questionários resultou em 5.220 respostas de escolha modal por motivo de viagem (Trabalho, $W$, ou Lazer, $L$ ). Isler e Pitombo (2014) apresentaram uma modelagem dos padrões das respostas apresentadas pelos participantes da pesquisa sob a abordagem de classificação por Árvores de Decisão, uma técnica não paramétrica que agrupa os dados em um número finito de classes de maneira hierárquica (Quinlan, 1983).

Entretanto, neste artigo, propõe-se um modelo Logit Multinomial (Ortúzar e Willumsen, 2011) para estimativa das probabilidades de escolha modal entre pares de cidades da Região Sudeste, calculadas segundo as respectivas funções utilidade caracterizadas entre a Equação (1) e a Equação (10) por motivo de viagem (Isler, 2015).

$$
\begin{gathered}
V_{C A R}^{W}=-0,00497 \cdot T T_{C A R}-0,00841 \cdot P E_{C A R}-0,00841 \cdot T O_{C A R} \\
V_{B U S}^{W}=-0,51200-0,00497 \cdot T T_{B U S}-0,00511 \cdot F R_{B U S}-0,00240 \cdot F A_{B U S} \\
V_{H P T}^{W}=-0,51200-0,00497 \cdot T T_{H P T}-0,00511 \cdot F R_{H P T}-0,00240 \cdot F A_{H P T} \\
V_{H S T}^{W}=-0,51200-0,00497 \cdot T T_{H S T}-0,00511 \cdot F R_{H S T}-0,00240 \cdot F A_{H S T} \\
V_{A I R}^{W}=-0,51200-0,00497 \cdot T T_{A I R}-0,00511 \cdot F R_{A I R}-0,00240 \cdot F A_{A I R} \\
V_{C A R}^{L}=-0,00788 \cdot T T_{C A R}-0,00261 \cdot P E_{C A R}-0,00261 \cdot T O_{C A R} \\
V_{B U S}^{L}=-0,00788 \cdot T T_{B U S}-0,00354 \cdot F A_{B U S} \\
V_{H P T}^{L}=-1,06000-0,00788 \cdot T T_{H P T}-0,00261 \cdot F A_{H P T} \\
V_{H S T}^{L}=-1,06000-0,00788 \cdot T T_{H S T}-0,00261 \cdot F A_{H S T} \\
V_{A I R}^{L}=-1,43000-0,00788 \cdot T T_{A I R}-0,00261 \cdot F A_{A I R}
\end{gathered}
$$

em que $V_{k}^{W}$ : parcela determinística da função utilidade pelo modo $k$ por motivo trabalho;

$V_{k}^{L}$ : parcela determinística da função utilidade pelo modo $k$ por motivo lazer;

$T T_{k}$ : tempo de viagem pelo modo de transporte $k$;

$P E_{k}$ : custo da viagem com combustível pelo modo de transporte $k$;

$T O_{k}$ : custo da viagem com pedágios pelo modo de transporte $k$;

$F R_{k}$ : frequência de serviços do modo de transporte $k$;

$F A_{k}$ : tarifa do modo de transporte $k$. 


\section{ANÁLISE CUSTO-BENEFÍCIO}

Na Análise Custo-Benefício para comparação da operação das tecnologias ferroviárias foram considerados como itens de custo os valores monetários dos investimentos na construção da infraestrutura (ICC) e aquisição dos trens $\left(R S C^{A}\right)$. As despesas foram caracterizadas pela operação do material rodante $\left(R S C^{0}\right)$ e manutenção da via permanente $\left(I C^{M}\right)$ e dos veículos $\left(R S C^{M}\right)$. Os benefícios econômicos foram admitidos como as receitas advindas da venda de passagens $(T R)$ e o valor residual da infraestrutura (TRV), e os benefícios sociais foram admitidos como o excedente do consumidor devido à tarifação (TCSUC) e tempo de viagem (TCSTS), redução de acidentes (TAR) e redução de externalidades (TER).

Os valores dos itens descritos foram estabelecidos em uma unidade monetária comum (R\$) e convertidos para valores correntes no ano de 2015 pelo cálculo do Valor Presente Líquido (NPV) em um horizonte de construção e operação dos respectivos sistemas ferroviários até o ano de 2050. Por exemplo, considera-se a Equação (12) para estimativa do NPV referente aos investimentos necessários para construção da rede ferroviária hipotética para operação de uma das tecnologias ferroviárias, referentes aos valores resultantes do modelo de traçados ferroviários descrito anteriormente.

$$
I C^{C}=\sum_{t=0}^{T_{0}-1} \frac{(1+\varphi) \cdot(1+\rho) \cdot C C}{T_{0} \cdot(1+M A R R)^{t}}
$$

em que $T_{0}=$ é o ano final do horizonte de planejamento (2050);

$\varphi=$ fator de correção pela variabilidade dos investimentos para construção do traçado;

$\rho=$ custo adicional devido ao planejamento e projeto do investimento;

$C C=$ investimento estimado para construção resultante do Algoritmo Genético;

$M A R R=$ taxa mínima de atratividade do investimento.

As medidas de desempenho consideradas na comparação entre tecnologias ferroviárias foram o "Valor Presente Líquido Total" (TNPV) e o "Valor Presente Líquido Econômico" (ENPV), este utilizado para comparar o NPV dos benefícios econômicos (receita operacional e valor residual) e custos econômicos (construção e manutenção da infraestrutura, e aquisição, operação e manutenção do material rodante) conforme a Equação (12) e Equação (13).

$$
\begin{gathered}
T N P V=(T R+T R V+T C S U C+T C S T S+T A R+T E R)-\left(I C^{C}+R S C^{A}+R S C^{O}+I C^{M}+R S C^{M}\right) \\
E N P V=(T R+T R V)-\left(I C^{C}+R S C^{A}+R S C^{O}+I C^{M}+R S C^{M}\right)
\end{gathered}
$$

Outra medida de desempenho comumente utilizada para comparação de projetos é a "Razão Benefício-Custo" (BCR) caracterizado por DfT (2014), que consiste na proporção de benefícios sociais de cada unidade de investimento e despesas conforme a Equação (14).

$$
B C R=\frac{T R V+T C S U C+T C S T S+T A R+T E R}{I C^{C}+I C^{M}+R S C^{A}+R S C^{O}+R S C^{M}}
$$

De Rus et al. (2009) sugerem que um projeto pode ser considerado viável no âmbito econômico e social quando o Valor Presente Líquido Total é positivo (TNPV $>0)$ e a Razão Benefício-Custo é maior ou igual a $1,50(B C R \geq 1,50)$.

\section{APLICAÇÃO DOS MODELOS}

A modelagem descrita nas seções anteriores foi aplicada a uma rede ferroviária hipotética conectando as cidades e regiões metropolitanas da Região Sudeste do Brasil segundo uma estruturação hierárquica dos centros urbanos brasileiros (Henderson, 2008), que inclui a Região Metropolitana de São Paulo (CGH), do Rio de Janeiro (SDU) e Belo Horizonte (PLU), e as cidades de Vitória (VIX), Campinas (VCP), São José do Rio Preto (SJP), Ribeirão Preto (RAO), Uberaba (UBA), Uberlândia (UDI), Juiz de Fora (JDF) e Montes Claros (MOC). 
Ao considerar a frequência de serviços ferroviários nas funções utilidade do modo de transporte foi necessário estabelecer eixos de operação dos trens para viabilizar o cálculo do número de trens diários para atender a demanda estimada, os quais são caracterizados na Figura 4 pelas diferentes cores de arcos conectando as cidades consideradas.

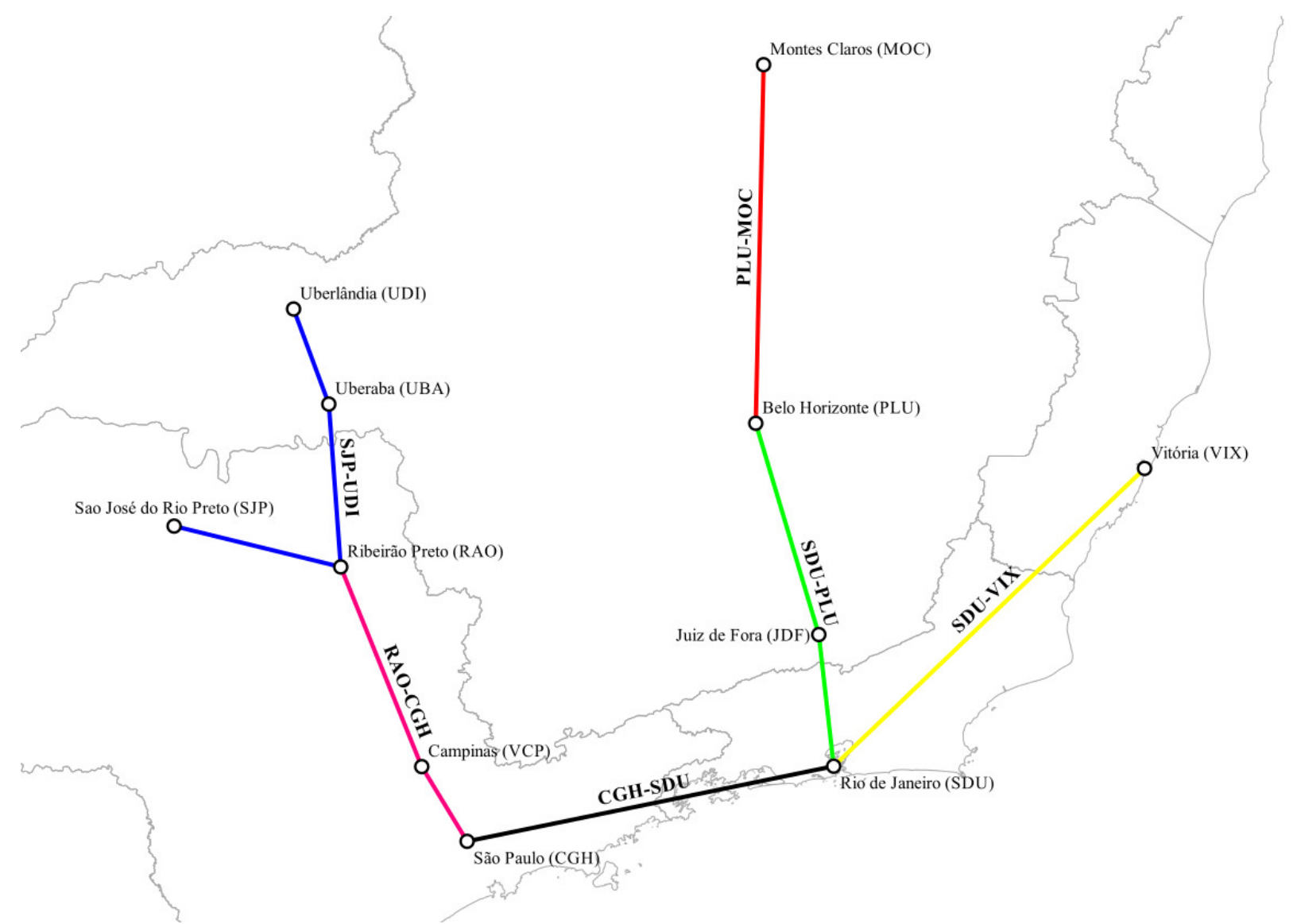

Figura 4: Proposta de rede para aplicação da Análise Custo-Benefício. Fonte: Isler (2015).

Dada a configuração da rede, os valores de investimentos necessários para construção de novos traçados foram estimados considerando diferentes parâmetros geométricos e de custos unitários em função da tecnologia ferroviária. Os valores obtidos pela aplicação do AG entre cidades da rede resultaram em 2.443,03 km de linhas para operação do HPT, perfazendo um investimento total de $\mathrm{R} \$ 90.950,11 \times 10^{6}$, ou seja, um $\mathrm{R} \$ 37,2 \times 10^{6} / \mathrm{km}$. Por outro lado, para um sistema de $H S T$, foi obtido um valor médio de $\mathrm{R} \$ 38,8 \times 10^{6} / \mathrm{km}$ para construção de $2.472,41 \mathrm{~km}$, resultando em investimento total de $\mathrm{R} \$ 95.825,94 \times 10^{6}$.

Esses resultados sugerem que a construção de uma rede para operação de HST incorre em aumento de $\mathrm{R} \$ 1,6 \times 10^{6} / \mathrm{km}(5,36 \%)$ no investimento total em relação ao HPT. Esse aumento pode ser considerado pequeno em relação aos benefícios de redução de tempo de viagem pela metade, pela variação da velocidade média de $150 \mathrm{~km} / \mathrm{h}$ para $300 \mathrm{~km} / \mathrm{h}$.

Para execução da Análise Custo-Benefício proposta neste artigo, as premissas sobre as condições de operação dos trens, os investimentos em construção e revitalização de estações ferroviárias, período de construção dos traçados ferroviários, caraterísticas dos modos de transporte alternativos ao ferroviário (automóvel, ônibus e avião) e demais características dos serviços podem ser consultadas em Isler (2015).

A estimativa do número total de viagens entre pares de cidades da rede foi realizada pelas projeções caracterizadas na seção 3 deste artigo no horizonte de planejamento entre 2015 e 2050 . Além disso, foi 
considerado um fator de majoração referente à geração de viagens que atualmente não são realizadas, mas que passariam a ocorrer pela disponibilidade dos trens.

A porcentagem de escolha modal pela oferta dos serviços ferroviários foi calculada mediante as funções utilidade entre a Equação (1) e a Equação (10), extrapolando-se a decisão individual caracterizada pela função Logit Multinominal para um nível agregado para toda a população das cidades da Figura 4. Assim, para calcular o número de usuários que potencialmente utilizariam o modo de transporte ferroviário, o número de viagens estimadas nos anos do horizonte de planejamento foi multiplicado pela probabilidade de escolha de cada um dos modos de transporte mediante os respectivos níveis dos atributos.

Assim como as premissas para caracterização da operação ferroviária e construção dos alinhamentos entre as cidades, o método de agregação dos valores que caracterizam os atributos envolvidos na escolha modal pode ser verificado na pesquisa de Isler (2015), sobretudo quanto à definição dos tempos de viagem (acesso, durante o trajeto e egresso).

\subsection{Resultados dos Cenários}

Dadas as incertezas inerentes à aplicação da Análise Custo-Benefício foram propostos três cenários de análise ("Otimista", "Intermediário" e "Conservador"), pela variação dos investimentos estimados, da produtividade de construção da infraestrutura e do tráfego gerado pela parcela da população que passaria a viajar após operação dos trens. Os parâmetros e método de cálculo do valor presente líquido dos itens da análise socioeconômica e, consequentemente, das medidas de desempenho que caracterizam a operação de cada tecnologia ferroviária podem ser verificados em Isler (2015).

Em cada cenário foram estabelecidas tarifas ferroviárias $(\mathrm{R} \$ / \mathrm{km})$ para as duas tecnologias consideradas neste artigo e foram calculados os valores de $T N P V, E N P V$ e $B C R$, resultando nos gráficos da Figura 5, Figura 6 e Figura 7, respectivamente.

A partir da Figura 5 observa-se que os valores estimados de TNPV no caso da operação de HST são expressivamente maiores do que para $H P T$, sobretudo para valores baixos de tarifa média. Essa medida de desempenho é negativa para tarifa média maior que $\mathrm{R} \$ 0,40 / \mathrm{km}, \mathrm{R} \$ 0,60 / \mathrm{km}$ e $\mathrm{R} \$ 0,80 / \mathrm{km}$ nos respectivos cenários Conservador, Intermediário e Otimista para a operação de HPT. A operação de HST resulta em valores negativos de $T N P V$ para tarifa média acima de $\mathrm{R} \$ 1,00 / \mathrm{km}, \mathrm{R} \$ 1,15 / \mathrm{km}$ e $\mathrm{R} \$ 1,30 / \mathrm{km}$ naqueles respectivos cenários.

Os resultados representados na Figura 6 indicam que o ENPV para a rede de $H S T$ em geral é maior que aquele para $H P T$ em cenários correspondentes às tarifas entre $\mathrm{R} \$ 0,50 / \mathrm{km}$ e $\mathrm{R} \$ 1,50 / \mathrm{km}$. Entretanto, mesmo para as tarifas que maximizam aquela medida de desempenho, todos os resultados econômicos são negativos, sendo o menos deficitário aquele com tarifa de $\mathrm{R} \$ 1,10 / \mathrm{km}$ no cenário Otimista para a operação de $H S T$ (R $\left.\$-35,14 \times 10^{9}\right)$.

Finalmente, a partir da Figura 7, infere-se que as tendências do BCR são semelhantes às do TNPV. No cenário Conservador para a operação de HPT a Razão Benefício-Custo é maior que 1,00 para tarifa média abaixo de $\mathrm{R} \$ 0,20 / \mathrm{km}$, no Intermediário para tarifa menor que $\mathrm{R} \$ 0,30 / \mathrm{km}$ e no cenário Otimista quando a tarifa é menor que $\mathrm{R} \$ 0,40 / \mathrm{km}$. Porém, em nenhum cenário para essa tecnologia o índice é maior que 1,50 recomendado por De Rus et al. (2009).

Em relação à rede de $H S T$, o $B C R$ é maior do que 1,00 e 1,50 quando as tarifas ferroviárias são respectivamente menores que $\mathrm{R} \$ 0,55 / \mathrm{km}$ e $\mathrm{R} \$ 0,15 / \mathrm{km}$ para o cenário Conservador, $\mathrm{R} \$ 0,65 / \mathrm{km}$ e $\mathrm{R} \$ 0,25 / \mathrm{km}$ para o Intermediário, e $\mathrm{R} \$ 0,75 / \mathrm{km}$ e $\mathrm{R} \$ 0,35 / \mathrm{km}$ para o Otimista. 

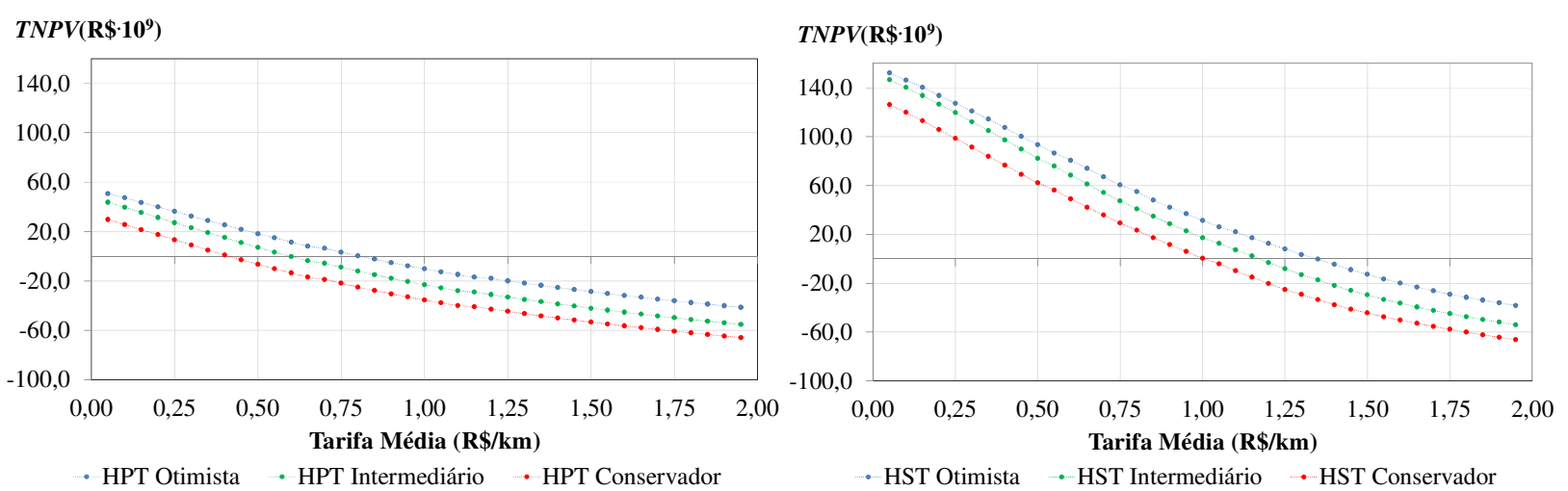

Figura 5: Resultados de TNPV para tarifas nos cenários da Análise Custo-Benefício. Fonte: Isler (2015).
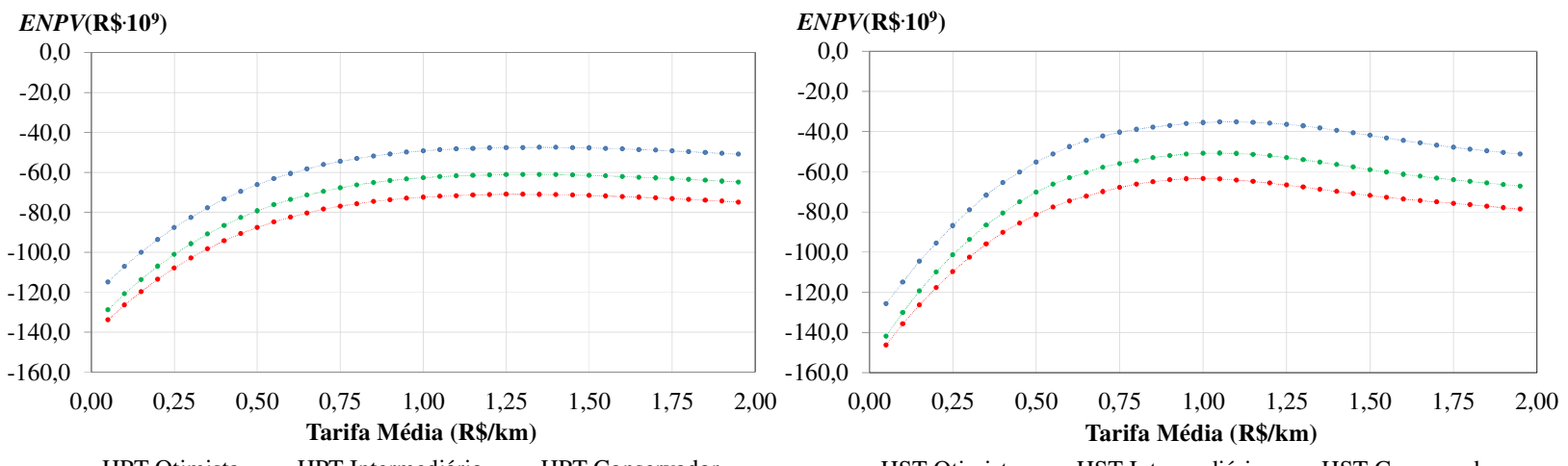

Figura 6: Resultados de ENPV para tarifas nos cenários da Análise Custo-Benefício. Fonte: Isler (2015).
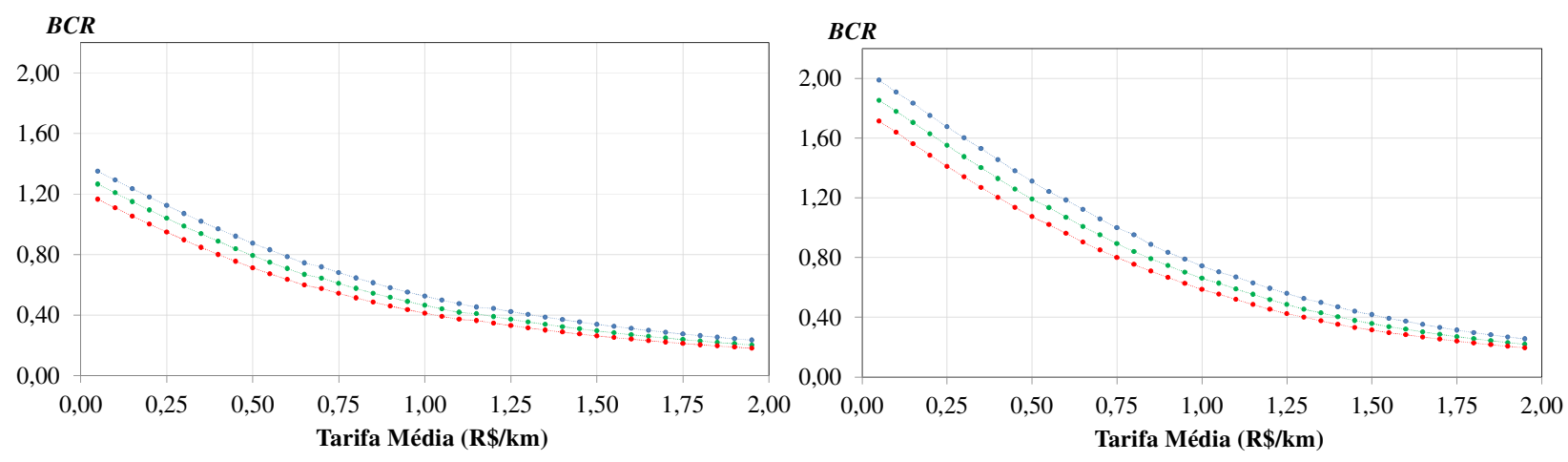

- HPT Otimista - HPT Intermediário - HPT Conservador

- HST Otimista - HST Intermediário - HST Conservador

Figura 7: Resultados de $B C R$ para tarifas nos cenários da Análise Custo-Benefício. Fonte: Isler (2015).

\subsection{Análise de Sensibilidade}

Além do cálculo das medidas de desempenho anteriores, foram realizadas análises do efeito da variação da porcentagem de valor residual dos investimentos em infraestrutura e da taxa mínima de atratividade sobre o Valor Presente Líquido Econômico (ENPV) e a Razão Benefício-Custo $(B C R)$.

Os gráficos a seguir representam os resultados ENPV e do BCR sob operação de HPT e HST mediante as respectivas tarifas que maximizam o ENPV (tarifa ótima) para os cenários intermediários analisados anteriormente, e variação da porcentagem de valor residual do investimento em infraestrutura (TRV) e da taxa mínima de atratividade dos investimentos (MARR).

Os gráficos anteriores sugerem que, para qualquer tecnologia ferroviária considerada, os benefícios econômicos não superam os investimentos de construção da infraestrutura e as despesas operacionais mesmo quando o valor residual é equivalente a 100\% daquele investimento inicial ao final do horizonte de planejamento. A mesma conclusão pode ser estabelecida sob o aspecto social, considerando que a infraestrutura é um bem público pertencente à sociedade, uma vez que os valores de $B C R$ estão aquém de 1,50 conforme recomendado por De Rus et al. (2009). 


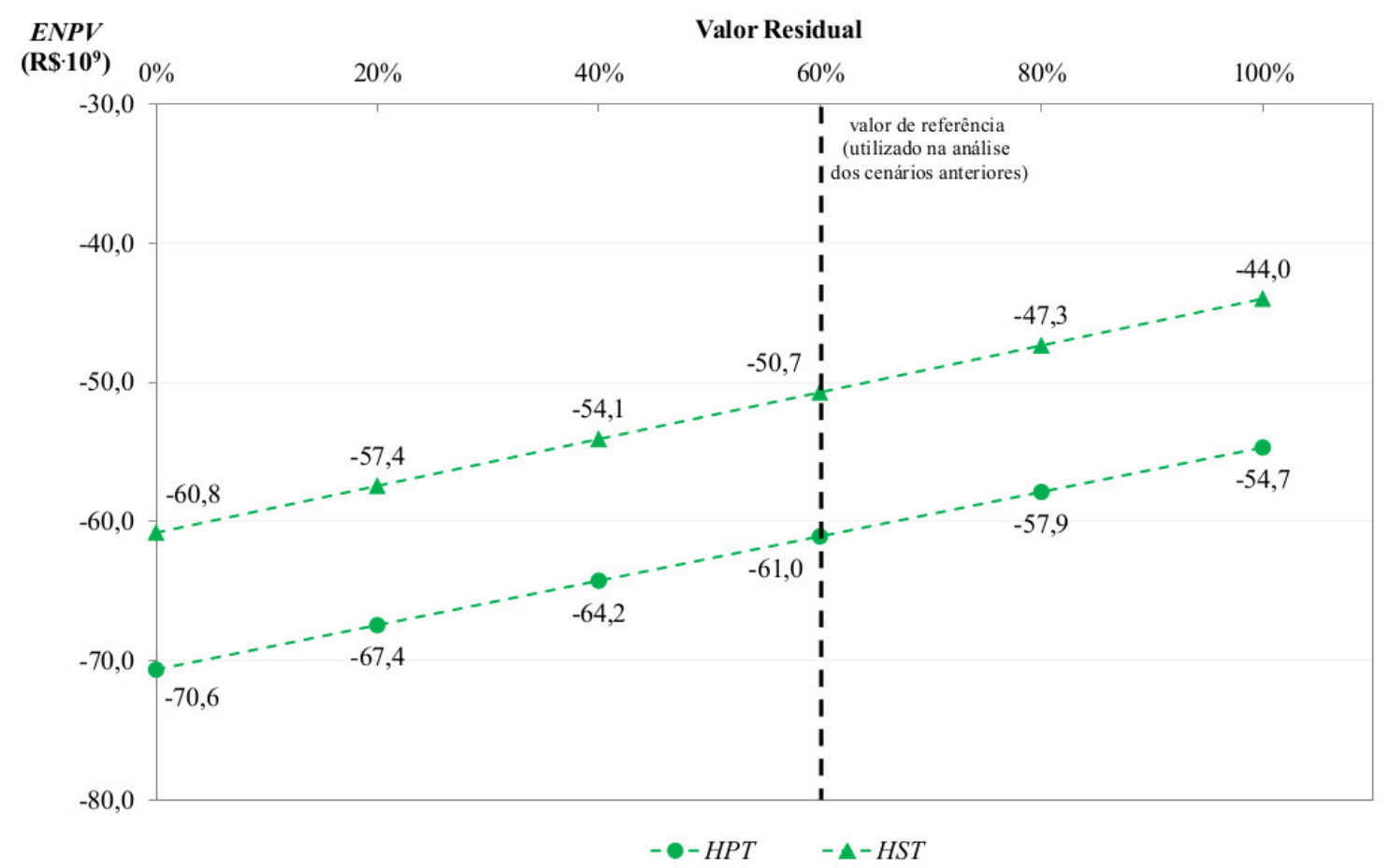

Figura 8: ENPV resultante da variação do valor residual dos investimentos em infraestrutura para o cenário Intermediário sob a tarifa ótima. Fonte: Isler (2015).

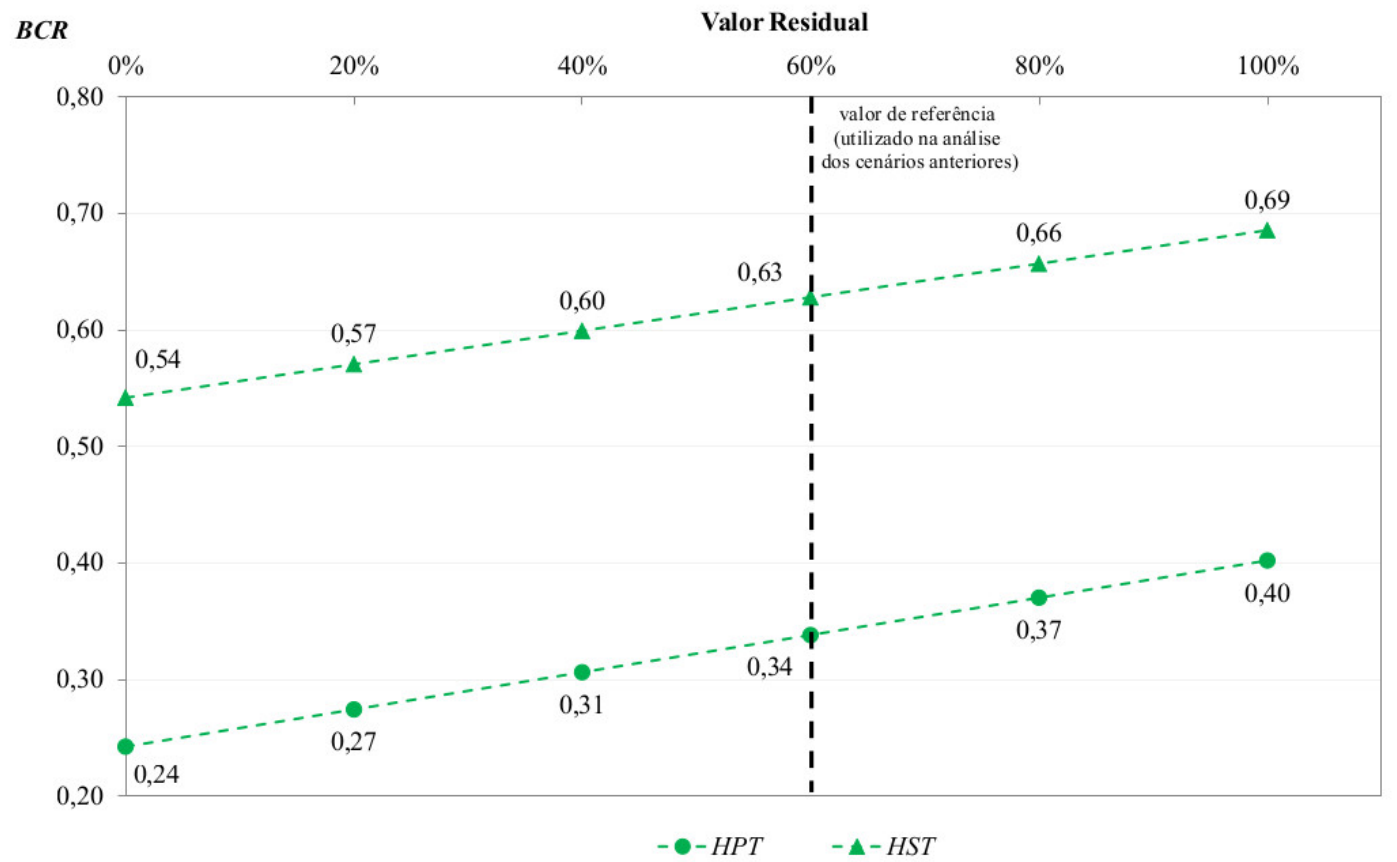

Figura 9: $B C R$ resultante da variação do valor residual dos investimentos em infraestrutura para o cenário Intermediário sob a tarifa ótima. Fonte: Isler (2015) 


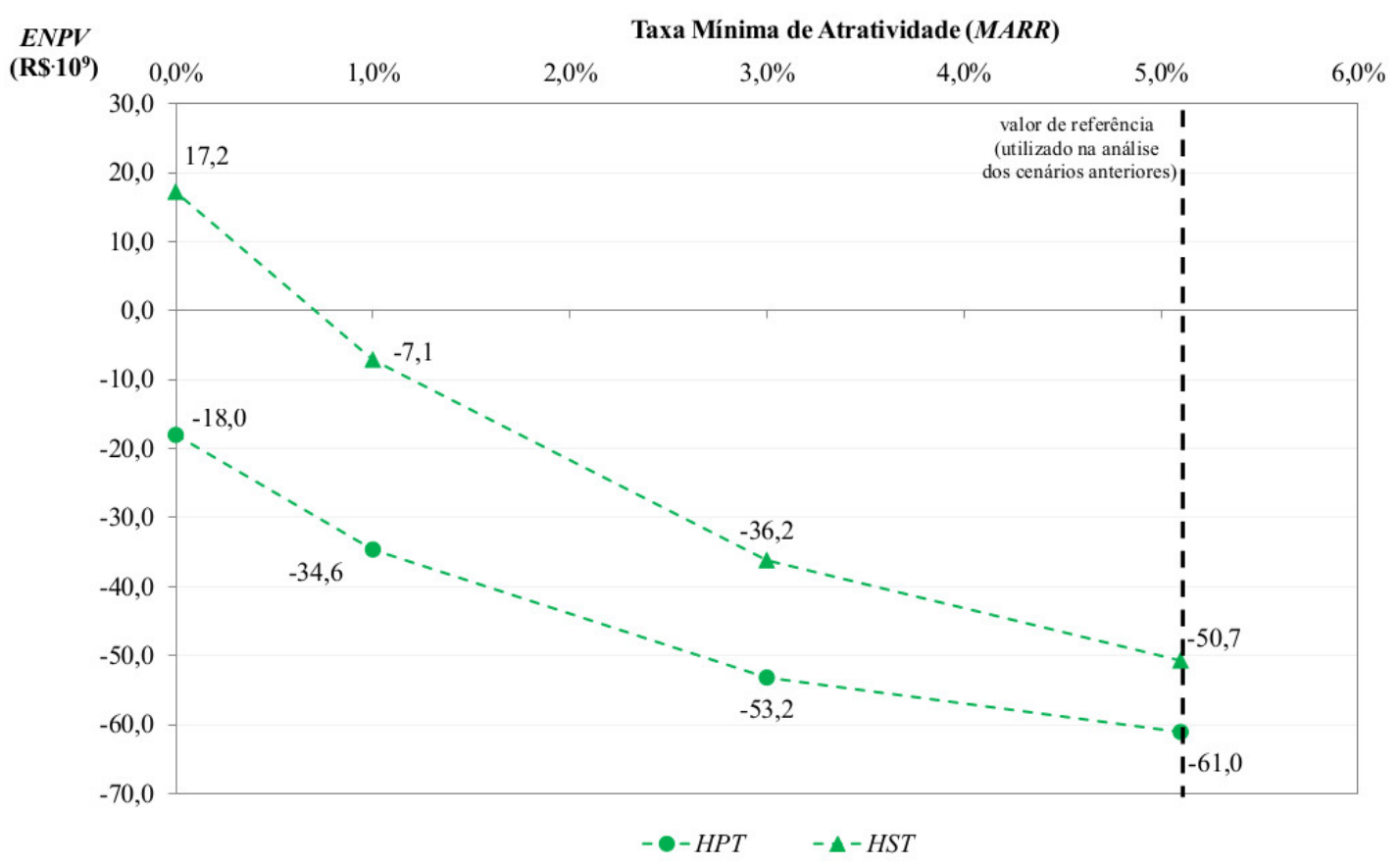

Figura 10: ENPV resultante da variação da taxa mínima de atratividade para o cenário Intermediário sob a tarifa ótima Fonte: Isler (2015)

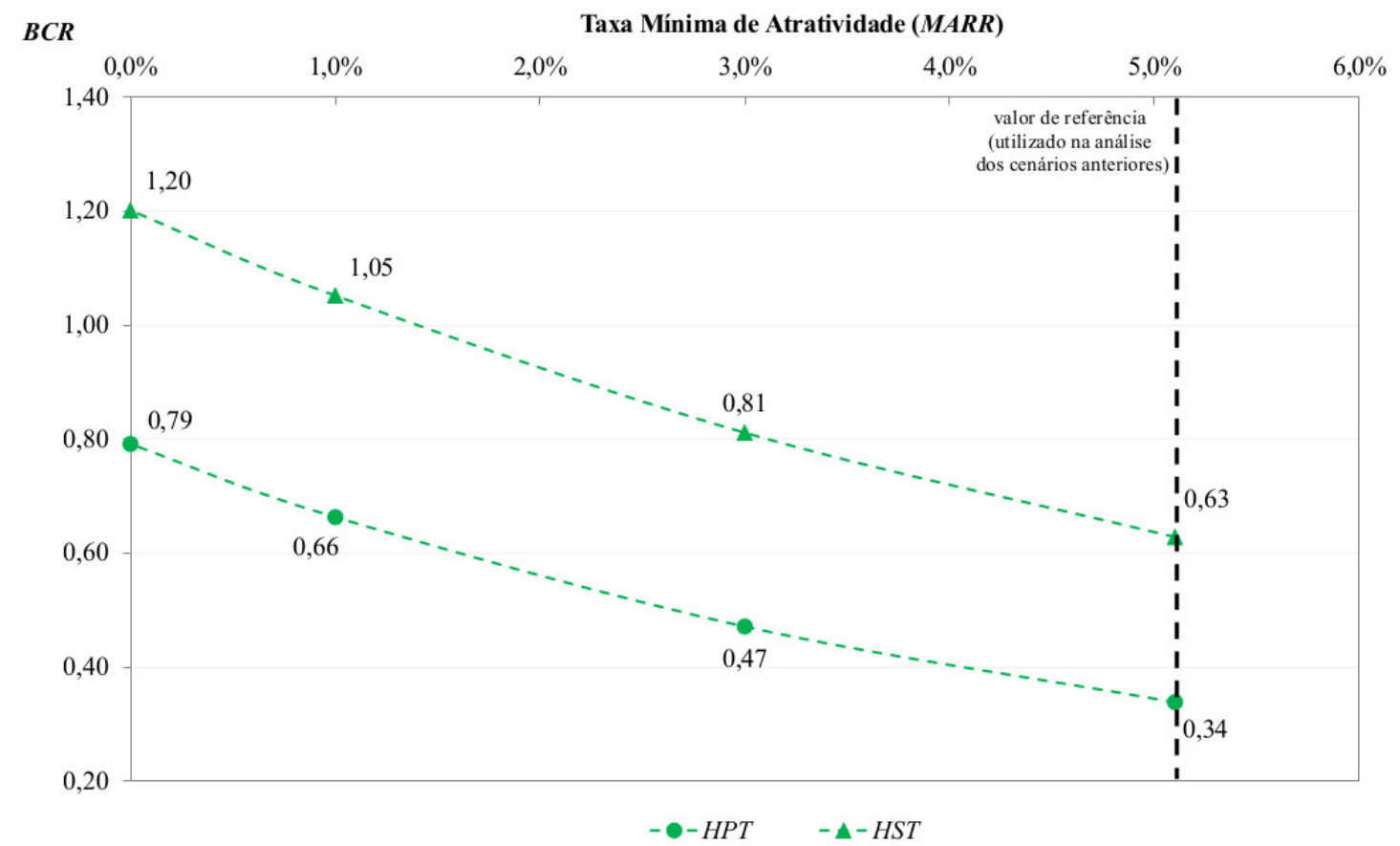

Figura 11: $B C R$ resultante da variação da taxa mínima de atratividade para o cenário Intermediário sob a tarifa ótima Fonte: Isler (2015)

Ao variar o parâmetro MARR observa-se uma tendência de aumento dos retornos econômicos e sociais dos projetos. Entretanto, somente para $H S T$ são constatados valores positivos de ENPV para taxas abaixo de 1,0\%, cujo $B C R$ é igual a 1,05 sob esse valor. Nessas considerações, é possível concluir que a operação de HPT não é viável pelo elevado investimento necessário para a construção da infraestrutura para operação desta tecnologia e pelos retornos econômico e social serem menores do que para a operação de $H S T$. 


\section{CONCLUSÕES E PESQUISAS FUTURAS}

O objetivo deste artigo é comparar a oferta de diferentes tecnologias ferroviárias para o transporte de passageiros em uma rede hipotética na Região Sudeste do Brasil considerando um método de Análise Custo-Benefício.

Os resultados obtidos sugerem que a construção e operação de qualquer uma das tecnologias analisadas (HPT ou HST) são inviáveis do ponto de vista estritamente econômico a menos que seja considerado um subsídio externo ao investimento. Sob a perspectiva socioeconômica, a operação de HPT não resulta em valores de relação entre benefícios sociais e custos econômicos maiores que 1,50 em nenhum dos cenários analisados, e a operação de HST provê valores maiores que essa referência para tarifas abaixo de $\mathrm{R} \$ 0,35 / \mathrm{km}$ em um cenário otimista.

Como pesquisas futuras sugere-se a aplicação de diferentes abordagens para estimativa dos parâmetros das funções utilidade de divisão modal (e.g., Nested Logit Multinomial), além da execução de análises socioeconômicas para redes alternativas à indicada neste artigo, pela inclusão de outras cidades da região Sudeste e diferentes conexões entre elas.

Finalmente, podem ser conduzidas investigações futuras sobre a configuração de conexões entre cidades na Região Sudeste que maximiza uma medida de desempenho específica, pela aplicação um modelo matemático para um problema de planejamento de redes.

\section{AGRADECIMENT? $S$}

Esta pesquisa foi financiada pelo Conselho Nacional de Desenvolvimento Científico e Tecnológico (CNPq).

\section{REFERÊNCIAS BIBLIOGRÁFICAS}

Aguiar Júnior, S. R. (2004) Modelo RAPIDE: uma aplicação de mineração de dados e redes neurais artificiais para a estimativa da demanda por transporte rodoviário interestadual de passageiros no Brasil. Dissertação (Mestrado) - Universidade Católica de Brasília, Brasília, DF.

Alekseev, K. P. G. e J. M. Seixas (2002) Forecasting the air transport demand for passengers with neural modelling. In: Proceedings of VII Brazilian Symposium on Neural Networks. Recife, Brazil, p. 86-91. DOI: 10.1109/SBRN.2002.1181440.

ANAC (1998) Agência Nacional de Aviação Civil - Demanda Global do Transporte Aéreo Brasileiro. http://www2.anac.gov.br/arquivos/pdf/ demandaGlobalTranspAer1998.pdf. Acessado em 17/04/2014.

ANAC (2012) Agência Nacional de Aviação Civil - Anuário do Transporte Aéreo: Dados Estatísticos e Econômicos de 2012. http://www2.anac.gov.br/arquivos/zip/Anuario2012.zip. Acessado em 12/11/2013.

ANTT (2011) Agência Nacional de Transportes Terrestres - Pesquisa Operacional: serviços interestaduais com extensão superior a $75 \mathrm{~km}$. http://propass.antt.gov.br/. Acessado em: 15/03/2014

Batista, C. N. O. (2006) Contribuição à Análise da Capacidade de Processamento de Trens Cargueiros em Linhas Ferroviárias Singelas no Brasil. Dissertação (Mestrado) - Departamento de Engenharia de Transportes, Escola de Engenharia de São Carlos, USP, São Carlos, SP.

Berechman, J. (2010) The evaluation of transportation investment projects. London: Routledge. DOI: $10.4324 / 9780203873281$.

Boardman, A. E.; D. Greenberg; A. Vining e David Weimer (2011). Cost-Benefit Analysis: Concepts and Practice. Upper Saddle River :Pearson-Prentice Hall.

Cascetta, E. e S. Nguyen (1988) A unified framework for estimating or updating origin/destination matrices from traffic counts. Transportation Research Part B: Methodological, Elsevier, v. 22, n. 6, p. 437-455. D0I: 10.1016/01912615(88)90024-0.

CPTM (2014) Programa de Investimentos em Trens Regionais. http: //www.cptm.sp.gov.br/Obras/trens-regionais.asp. Acesso em: $21 / 08 / 2014$.

Crainic, T. G.; T. Davidovic e D. Ramljak (2012) Designing parallel meta-heuristic methods. In: Despotovic-Zrakic, M.; V. Milutinovic e A. Belic (Ed.) Handbook of Research on High Performance and Cloud Computing in Scientific Research and Education. Québec, Canada: IGI Global. DOI: 10.4018/978-1-4666-5784-7.ch011.

De Rus, G. e G. Nombela (2007) Is investment in high speed rail socially profitable? Journal of Transport Economics and Policy, JSTOR, v. 41, n. 1, p. 3-23.

De Rus, G.; I. Barrón; J. Campos; P. Gagnepain; C. Nash; A. Ulied e R. Vickerman (2009) Economic analysis of high speed rail in Europe. Spain: Fundación BBVA.

DfT (2014) Transport Analysis Guidance - WebTAG. https://www.gov.uk/transport-analysis-guidance-webtag. UK Department for Transport's website for guidance on the conduct of transport studies.

Dreyer, S. B. (2010) Comparative Analysis of the Quality of Appraisal Practices for High Speed Rail Investments Projects in Europe. Dissertação (Mestrado) - Molde University College, Molde, Norway. 
Gleave, S. D. (2004) High Speed Rail: International Comparisons. London: Commission for Integrated Transport.

Gonçalves, M. B.; E. T. Bez e A. G. Novaes (2007). Modelos econométricos aplicados à previsão de demanda por transporte interestadual de passageiros de ônibus no Brasil. Transportes, v. 15, n. 1, p. 24-33.

Hashem, I. A. T.; I. Yaqoob; N. B. Anuar; S. Mokhtar; A. Gani e S. U. Khan (2015) The rise of "big data"on cloud computing: Review and open research issues. Information Systems, Elsevier, v. 47, p. 98-115. DOI: 10.1016/j.is.2014.07.006.

Henderson, J. V. (2008) Regiões de influência das cidades 2007. Rio de Janeiro: IBGE.

IBGE (2014a). Instituto Brasilero de Geografia e Estatística - WebCart. http://www.ibge.gov.br/webcart/. Acessado em 23/02/2014.s_1980_2050.zip. Acessado em 20/03/2014.

IBGE (2014b) Instituto Brasilero de Geografia e Estatística - Projeção de Crescimento da População Brasileira. http://servicodados.ibge.gov.br/Download/Download.ashx?u=ftp.ibge.gov.br/Projecao_da_Populacao/Revisao_2008_Projecoes_1980_2050/Estimativa. Acessado em 13/04/2014.

Isler, C. A. (2010) Proposta de um Modelo de Capacidade de Processamento de Trens Cargueiros em Redes Ferroviárias de Linha Singela. Dissertação (Mestrado) - Departamento de Engenharia de Transportes, Escola de Engenharia de São Carlos, USP, São Carlos, SP.

Isler, C. A. e C. S. Pitombo (2014) Avaliação da escolha modal para o transporte ferroviário de passageiros na região sudeste através de árvores de decisão. In: Anais do XXVIII Congresso da ANPET - Associação Nacional de Pesquisa e Ensino em Transportes. Curitiba, PR: ANPET.

Isler, C.A. (2015) Avaliação socioeconômica de uma rede ferroviária regional para o transporte de passageiros. 299 p. Tese de Doutorado - Escola de Engenharia de São Carlos, Universidade de São Paulo.

Jha, M. K.; P. Schonfeld; J.-C. Jong e E. Kim (2006) Intelligent Road Design. Boston: WIT Press.

Jong, J. C. e P. Schonfeld (2003) An evolutionary model for simultaneously optimizing three-dimensional highway alignments. Transportation Research Part B: Methodological, Elsevier, v. 37, n. 2, p. 107-128. DOI: 10.1016/S0191-2615(01)00047-9.

Kang, M.; M. K. Jha e P. Schonfeld (2012) Applicability of highway alignment optimization models. Transportation Research Part C: Emerging Technologies, Elsevier, v. 21, n. 1, p. 257-286. DOI: 10.1016/j.trc.2011.09.006.

Kim, E.; M. K. Jha e B. Son (2005) Improving the computational efficiency of highway alignment optimization models through a stepwise genetic algorithms approach. Transportation Research Part B: Methodological, Elsevier, v. 39, n. 4, p. 339-360. DOI: 10.1016/S0191-2615(04)00084-0.

Lai, X.; Schonfeld, P. (2016) Concurrent Optimization of Rail Transit Alignments and Station Locations. Urban Rail Transit, Springer, v. 2, n.1, p. 1-15. D0I: 10.1007/s40864-016-0033-1.

Livra (2013) Pesquisas online. http://www.livra.com/. Acessado em: 08/08/2013.

MPS (2013) Ministério da Previdência Social - Projeções Atuariais para o Regime Geral de Previdência Social. http://www12.senado.gov.br/orcamento/documentos/ldo/2014/elaboracao/projeto-de-lei/2014/anexo-iv.5-2013-projecoes-atuariais-para-o-regime-geral-de-previdencia-social-2013. Acessado em 16/12/2013.

Munasinghe, M. (2007) Multi-criteria analysis in environmental decision-making. Washington: Environmental Information Coalition, National Council for Science and the Environment.

NuvemUSP (2013) Ambiente de infraestrutura em nuvem da Universidade de São Paulo. https://nuvem.uspdigital.usp.br/. Acessado em 15/10/2013.

Ortúzar, J. D. e L. G. Willumsen (2011) Modelling transport. 4. ed. [S.I.]: John Wiley \& Sons Ltd. DOI: 10.1002/9781119993308.

Pitombeira Neto, A. R.; B. V. Bertoncini e C. F. G. Loureiro (2011) Abordagem bayesiana na estimação de matrizes origem-destino sintéticas em redes de transportes. Anais do XXV Congresso da ANPET - Associação Nacional de Pesquisa e Ensino em Transportes. Belo Horizonte: ANPET.

PNLT (2014) Ministério dos Transportes - Plano Nacional de Logística e Transporte. http://www2.transportes.gov.br/bit/01inicial/pnlt.html. Acessado em 10/03/2014.

Qualtrics (2013) Qualtrics Online Surveys. www.qualtrics.com/. Acessado em 20/09/2013.

Quinlan, J. R. (1983) Learning efficient classification procedures and their application to chess end games. In: Michalski, R. S.; J. G. Carbonell e T. M. Mitchell (Ed.). Machine learning. [S.I.]: Springer, (Symbolic Computation). p. 463-482. DOI: 10.1007/978-3-662-12405-5_15.

Samanta, S. e M. K. Jha (2011) Modeling a rail transit alignment considering different objectives. Transportation Research Part A: Policy and Practice, Elsevier, v. 45, n. 1, p. 31-45. DOI: 10.1016/j.tra.2010.09.001.

Sartori, D.; G. Catalano; M. Genco; C. Pancotti; E. Sirtori; S. Vignetti e C. Del Bo (2004) Guide to cost-benefit analysis of investment projects. Brussels: European Commission, DG Regional Policy.

TAV (2014) Trem de Alta Velocidade no Brasil. http://portal.antt.gov.br/index.php/content/view/5448/Trem_de_Alta_Velocidade__TAV.html

Wang, J. J.; C. Rong; J. Xu e S. W. O. Or (2012) The funding of hierarchical railway development in China. Research in Transportation Economics, Elsevier, v. 35, n. 1, p. 26-33. DOI: 10.1016/j.retrec.2011.11.004. 